\title{
Exigência de Proteína para o Escargot Francês, Helix aspersa maxima em Fase de Crescimento
}

\author{
Claudemir Martins Soares ${ }^{1 *}$, Carmino Hayashi $^{2}$, Igor Consoni Cocito ${ }^{3}$
}

\begin{abstract}
RESUMO - Com o objetivo de determinar a exigência de proteína bruta (PB) em dietas para o "escargot" francês (Helix aspersa maxima), 200 animais com peso inicial médio de 2,00 g foram distribuídos em um experimento inteiramente casualizado com quatro tratamentos $[12,00 ; 15,00 ; 18,00$ e $21,00 \%$ de PB] e cinco repetições, com 10 animais por unidade experimental, durante 90 dias. Foi observado efeito quadrático dos teores de PB sobre o peso final médio, a conversão alimentar, taxa de eficiência protéica, porcentagem de concha e rendimento de carcaça com os melhores valores nos teores de 16,23; 16,95; 14,79; 16,07 e 15,87\% de PB, respectivamente. A taxa de sobrevivência não foi afetada pelos teores de PB utilizados. Concluiu-se que a exigência de PB em dietas para "escargot" francês é de $16,23 \%$.
\end{abstract}

Palavras-chave: Escargot, "gros gris”, helicicultura, Helix aspersa maxima, proteína bruta

\section{Protein Requirement for Helix aspersa maxima during the Growing Phase}

\begin{abstract}
Aiming to determinate the dietary crude protein (CP) requirements for Helix aspersa maxima snail, 200 animals, with average initial weight of $2.00 \mathrm{~g}$ were used, and assigned to a completely randomized design with four treatments [12.00, 15.00, 18.00, and $21.00 \% \mathrm{CP}$ ] and five replicates of 10 animals per experimental unit, during a period of 90 days. It was observed a quadratic effect of CP levels on final mean weight, feed conversion, protein efficiency rate, shell percentage and carcass yield with the best values for $16.23,16.95,14.79,16.07$, and $15.87 \% \mathrm{CP}$, respectively. The CP levels did not affect the survival rate. It may be concluded that the requirement of $\mathrm{CP}$ on diets for the Helix aspersa maxima is $16.23 \%$.
\end{abstract}

Key Words: crude protein, "gros gris”, heliciculture, Helix aspersa maxima, snail

\section{Introdução}

O "escargot" é amplamente utilizado na alimentação humana, em vários países da Europa, sendo a França o principal consumidor e produtor (Barrier, 1982; Rousselet, 1986; Ferraz, 1999). No Brasil, a helicicultura tem sido indicada como opção de cultivo alternativo, podendo ser uma fonte extra de renda em pequenas propriedades, ou mesmo nas cidades. Entre as espécies mais utilizadas no Brasil destacam-se o "gros gris" (Helix aspersa maxima) e o caracol africano (Achatina fulica) (Rodrigues, 1991; Ferraz, 1999). Entretanto, não se conhece muitos dos aspectos relacionados às suas exigências nutricionais (Cuellar, 1986; Hayashi et al., 2000) sendo, conforme Hanssen (1989), inexistentes dietas adequadas para a criação de caracóis comestíveis. Dessa forma, são de relevada importância pesquisas que visem subsidiar dados para a formulação de dietas para estes animais.
De acordo com Ribas (1986), entre as vantagens de se utilizar dietas artificiais em substituição aos vegetais na helicicultura se destacam o melhor crescimento dos animais, melhor higienização do ambiente de criação, facilidade de armazenamento e na economia de espaço. Monney (1994) observou que indivíduos de A. fulica que receberam dieta artificial com $16,00 \%$ de proteína bruta (PB), associada a vegetais, tiveram crescimento mais elevado e atingiram a maturidade reprodutiva mais rapidamente, do que animais que receberam apenas dieta artificial ou vegetais.

Entre as pesquisas realizadas com caracóis comestíveis em condições tropicais estão os estudos sobre preferência alimentar e biologia de A. fulica, como o de Monney (1994), sendo raros os estudos sobre aspectos nutricionais, como níveis e fontes de cálcio na dieta e instalações e manejo (Melo et al., 1991; Hayashi et al., 1997; Lobão et al., 1988; Hayashi et al., 1998a; Hayashi et al., 1998b; Pacheco et al.,

\footnotetext{
${ }^{1}$ Biólogo MSc. do Departamento de Biologia / Universidade Estadual de Maringá.

2 Professor Dr Titular do Departamento de Biologia / Universidade Estadual de Maringá, E-mail: chayashi@uem.br

${ }^{3}$ Curso de Graduação em Agronomia do Departamento de Agronomia / Universidade Estadual de Maringá.

*Av. Colombo 5790, Jardim Universitário, Maringá PR, Brasil, CEP 97020-900, E-mail: cmsoares@ @em.br; Fone/Fax: (0xx44) 2637933
} 
1998), níveis e fontes protéicas nas dietas (Soares et al., 1999; Hayashi et al., 2000) e reprodução (Hayashi et al., 1997). Nota-se, entretanto, que são ainda mais escassas pesquisas com o cultivo do $H$. aspersa maxima, principalmente em relação à determinação de sua exigência nutricional, para que se possa formular dietas adequadas para desempenho satisfatório e com redução de custos de produção. Têm-se utilizado dietas empíricas (misturas de concentrados elaboradas para aves e fontes de cálcio ou dietas a base de restos vegetais) nas criações de ambas as espécies, as quais devem apresentar diferenças quanto à suas exigências nutricionais.

A alimentação é um dos principais fatores no custo de produção animal, sendo que entre seus componentes, os alimentos protéicos são os mais onerosos. Dessa forma, a determinação da exigência protéica implica em redução de custos. Considerando-se a possibilidade de obter bons índices de conversão alimentar com o uso de dieta completa (Ribas, 1986; Soares et al. 1999; Ferraz, 1999; Hayashi et al., 2000), a determinação do nível adequado de proteína é importante para melhor aproveitamento alimentare racionalização de custos de produção. Marks \& Jess (1994) indicam que, para o $H$. aspersa maxima, dietas com teores acima de 17,00\% de PB reduzem o consumo sem melhorar seu crescimento e conversão alimentar. Entretanto, estudos relacionados ao teor protéico em dietas para o $H$. aspersa, em condições tropicais, são inexistentes.

Em estudo com A. fulica, Soares et al. (1999) observaram melhores índices de ganho de peso e conversão alimentar com os valores estimados de 18,26 e $18,12 \%$ de PB, respectivamente. Avaliando o uso de diferentes fontes protéicas, Hayashi et al. (2000) indicaram os farelos de soja e de girassol como os alimentos protéicos mais adequados para as dietas destes animais.

O objetivo do presente estudo foi avaliar o efeito de diferentes teores de proteína bruta nas dietas sobre o desempenho, assim como determinar a exigência de proteína bruta para o escargot francês (Helix aspersa maxima).

\section{Material e Métodos}

O presente experimento foi realizado nas instalações do Laboratório de Zoologia Aplicada do Departamento de Biologia da Universidade Estadual de Maringá, entre junho e setembro de 2000, com dura- ção de 90 dias. Duzentos "escargots", com cerca de

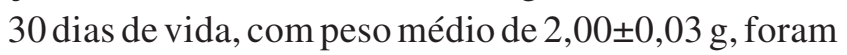
distribuídos em 20 aquários de vidro com capacidade para $12 \mathrm{~L}$ cada com 24,50; 14,50; e 29,50 cm de altura, largura e comprimento, respectivamente, dispostos em uma estante de aço e mantidos cobertos com plástico escuro. O delineamento experimental utilizado foi o inteiramente casualizado com quatro tratamentos e cinco repetições, considerando-se como repetição o aquário com 10 animais.

As dietas experimentais foram isocálcicas, isofosfóricas e isoaminoacídicas para lisina e metionina + cistina. Entretanto diferindo quanto aos teores de proteína bruta, sendo utilizados os teores de 12,$00 ; 15,00 ; 18,00 ;$ e 21,00\% (Tabela 1). Para a confecção das dietas, os ingredientes (milho, farelo de soja e bagaço de cana) foram moídos em um moinho tipo faca, com peneira com $0,50 \mathrm{~mm}$ de abertura, enquanto a farinha de ostra e o fosfato bicálcico foram moídos em moinho manual, de modo a apresentarem-se com diâmetro máximo de $0,25 \mathrm{~mm}$. Após a mistura dos ingredientes, as dietas foram acondicionadas em sacos plásticos, conservados em geladeira $\left( \pm 5,00^{\circ} \mathrm{C}\right)$.

$\mathrm{O}$ fornecimento de água e dieta foi realizado à vontade, sendo que, diariamente, os comedouros eram monitorados para a adição de dieta e manutenção da umidade, realizando-se retirada das fezes e pulverização de água. Caso houvesse dieta com alta umidade, a mesma era retirada e seca em estufa de ventilação forçada a $105^{\circ} \mathrm{C}$ por 48 horas, para pesagem e para o cálculo da conversão alimentar.

Ao final do experimento, suspendeu-se o fornecimento das dietas experimentais para os animais, sendo então estes alimentados com fubá de milho por 48 horas. Após um período de 24 horas em jejum, os animais foram pesados, sendo que, de cada unidade experimental, foram abatidos 50 animais, de acordo com a metodologia descrita por Barrier (1982). Durante o abate, estes foram colocados em solução de 8:1:1 de água, vinagre e sal comum, respectivamente, por cinco minutos. Essa operação foi realizada duas vezes para a retirado do muco. Em seguida, os animais foram lavados em água corrente e colocados em água fervendo por cinco minutos e novamente lavados, antes da retirada da concha e vísceras.

As variáveis avaliadas ao final do período experimental foram: peso final médio, ganho de peso médio, conversão alimentar, taxa de eficiência protéica, rendimento de carcaça e porcentagem de 
Tabela 1 - Composição percentual e química das dietas experimentais, com diferentes teores de proteína bruta (matéria natural) ${ }^{1}$

Table 1 - Chemical and percent composition of experimental diets with different crude protein level (as fed) ${ }^{1}$

\begin{tabular}{|c|c|c|c|c|}
\hline \multirow[b]{2}{*}{$\begin{array}{l}\text { Ingrediente, } \% \\
\text { Ingredient }\end{array}$} & \multicolumn{4}{|c|}{$\begin{array}{c}\text { Proteína bruta na dieta }(\%) \\
\text { Dietary crude protein level }\end{array}$} \\
\hline & 12 & 15 & 18 & 21 \\
\hline Milho & 62,82 & 53,46 & 44,09 & 34,71 \\
\hline \multicolumn{5}{|l|}{ Corn } \\
\hline Farelo de soja & 12,32 & 21,40 & 30,48 & 39,57 \\
\hline \multicolumn{5}{|l|}{ Soybean meal } \\
\hline Bagaço de cana & 4,19 & 3,54 & 2,89 & 2,24 \\
\hline \multicolumn{5}{|l|}{ Sugar cane bagasse } \\
\hline DL-metionina-99\% & 0,27 & 0,18 & 0,09 & 0,00 \\
\hline \multicolumn{5}{|l|}{ DL-methionine } \\
\hline Óleo de soja & 0,37 & 1,84 & 3,31 & 4,79 \\
\hline \multicolumn{5}{|l|}{ Soybean oil } \\
\hline \multicolumn{5}{|l|}{ L-lysine } \\
\hline \multicolumn{5}{|l|}{ Shellflour } \\
\hline Fosfato bicálcico & 12,21 & 12,06 & 11,91 & 11,76 \\
\hline \multicolumn{5}{|l|}{ Dicalcium phosphate } \\
\hline Supl. min. vit. ${ }^{2}$ & 0,50 & 0,50 & 0,50 & 0,50 \\
\hline \multicolumn{5}{|l|}{ Mineral and vitamin mix ${ }^{2}$} \\
\hline Sal comum & 0,50 & 0,50 & 0,50 & 0,50 \\
\hline \multicolumn{5}{|l|}{ Salt } \\
\hline Total & 100,00 & 100,00 & 100,00 & 100,00 \\
\hline \multicolumn{5}{|l|}{ Total } \\
\hline EM/aves, kcal/kg ${ }^{1}$ & 2510 & 2510 & 2510 & 2510 \\
\hline \multicolumn{5}{|l|}{ ME/chicken } \\
\hline Proteína bruta, $\%$ & 12,00 & 15,00 & 18,00 & 21,00 \\
\hline \multicolumn{5}{|l|}{ Crude protein } \\
\hline Lisina, $\%$ & 1,22 & 1,22 & 1,22 & 1,22 \\
\hline \multicolumn{5}{|l|}{ Lisine } \\
\hline Metionina+cistina, $\%$ & 0,75 & 0,75 & 0,75 & 0,75 \\
\hline \multicolumn{5}{|l|}{ Methionine + cystine } \\
\hline Cálcio,\% & 5,00 & 5,00 & 5,00 & 5,00 \\
\hline \multicolumn{5}{|l|}{ Calcium } \\
\hline Fósforo total, \% & 2,50 & 2,50 & 2,50 & 2,50 \\
\hline \multicolumn{5}{|l|}{ Total phosphorous } \\
\hline Fibra bruta,$\%$ & 3,50 & 3,50 & 3,50 & 3,50 \\
\hline Crude fiber & & & & \\
\hline
\end{tabular}


concha. Para determinar a taxa de eficiência protéica, foi utilizada a expressão descrita por Jauncey \& Ross (1982).

$$
T E P=\frac{G P}{P C}
$$

em que: TEP = taxa de eficiência protéica; $\mathrm{GP}=$ ganho de peso $; \mathrm{PC}=$ proteína consumida .

Para determinar a porcentagem de concha, utilizou-se a expressão descrita por Soares et al. (1999):

$$
\% C c h=\frac{P c h}{P v} \times 100
$$

em que: $\% \mathrm{Cch}=$ percentagem de concha; $\mathrm{Pch}=$ peso médio das conchas; $\mathrm{Pv}=$ peso médio dos animais vivos.

Para determinar o rendimento de carcaça, foi utilizada a expressão:

$$
R C=\frac{P c a}{P v} \times 100
$$

em que: $\mathrm{RC}=$ rendimento de carcaça; $\mathrm{Pca}=$ peso médio da carne; $\mathrm{Pv}=$ peso médio dos animais vivos.

O modelo estatístico utilizado para as análises das variáveis estudadas foi:

$$
Y_{i j}=\mu+b_{1}\left(N_{i}-N\right)+b_{2}\left(N_{i}-N\right)^{2}+e_{i j}
$$

em que: $Y_{i j}=$ observação referente ao aquário j onde se utilizou o teor de proteína $\mathrm{i} ; \mu=$ constante geral; $\mathrm{b}_{1}=$ coeficiente linear de regressão da variável $\mathrm{Y}$, em função do teor de proteína $i ; b_{2}=$ coeficiente quadrático de regressão da variável Y, em função do teor de proteína $\mathrm{i} ; \mathrm{N}_{\mathrm{i}}=$ teor de proteína bruta na dieta $\mathrm{i}$; $\mathrm{N}=$ média dos teores de proteína bruta nas dietas; $e_{i j}=$ desvio aleatório associado a cada observação $Y_{i j}$.

Para as análises estatísticas dos dados, realizou-se análise de variância e de regressão (1,00\% de probabilidade) pelo programa computacional SAEG (Sistema de Análises Estatísticas e Genéticas), descrito por Euclydes (1983).

\section{Resultados e Discussão}

Os valores médios das características de desempenho do escargot francês, submetidos a dietas com diferentes teores de proteína bruta (PB), estão apresentados na Tabela 2 e Figura 1. Observou-se efeito quadrático $(\mathrm{p}<0,001)$ dos teores de PB sobre o peso final médio dos animais, com valor máximo estimado em 16,07\% de PB na dieta. Soares et al. (1999) observaram comportamento similar dessa variável,

\begin{tabular}{|c|c|c|c|c|c|}
\hline \multirow[b]{2}{*}{$\begin{array}{l}\text { Característica } \\
\text { Characteristic }\end{array}$} & \multicolumn{5}{|c|}{$\begin{array}{c}\text { Proteína bruta na dieta }(\%) \\
\text { Dietary crude protein level }\end{array}$} \\
\hline & 12 & 15 & 18 & 21 & $\mathrm{CV}$ \\
\hline $\begin{array}{l}\text { Peso inicial, } \mathrm{g} \\
\text { Initial weight }\end{array}$ & 2,00 & 2,00 & 2,00 & 2,00 & 0,00 \\
\hline $\begin{array}{l}\text { Peso final }{ }^{1}, \% \\
\text { Final weight }\end{array}$ & 10,93 & 12,89 & 13,25 & 10,05 & 10,80 \\
\hline $\begin{array}{l}\text { Conversão alimentar }{ }^{2} \\
\text { Feed/gain }\end{array}$ & 1,38 & 0,92 & 0,97 & 1,19 & 9,73 \\
\hline $\begin{array}{l}\text { Taxa eficiência protéica }{ }^{3} \\
\text { Protein efficiency rate }\end{array}$ & 1,65 & 1,38 & 1,75 & 2,50 & 9,50 \\
\hline $\begin{array}{l}\text { Concha }{ }^{4}, \% \\
\text { Shell }\end{array}$ & 11,12 & 9,16 & 8,73 & 12,69 & 19,62 \\
\hline $\begin{array}{l}\text { Rendimento de carcaça }{ }^{5}, \% \\
\text { Carcass yield }\end{array}$ & 36,56 & 34,63 & 33,99 & 37,30 & 6,91 \\
\hline $\begin{array}{l}\text { Sobrevivência**,\% } \\
\text { Survival rate }\end{array}$ & 94,00 & 97,50 & 92,00 & 93,33 & 8,72 \\
\hline
\end{tabular}

Tabela 2 - Valores médios das características de desempenho do escargot francês (Helix aspersa maxima) submetidos a dietas, com diferentes teores de proteína bruta*

Table 2 - Average performance characteristic values of snail (Helix aspersa maxima) fed diets with different protein level*

\footnotetext{
${ }_{1}^{1}$ efeito quadrático (quadratic effect): $Y=-24,5649+4,6809 X-0,1442 X^{2} ; r^{2}=0,56$

2 efeito quadrático (quadratic effect): $Y=6,2757-0,6336 X+0,0187 X^{2} ; r^{2}=0,76$

$3^{3}$ efeito quadrático (quadratic effect): $Y=7,6637-0,8440 X+0,0285 X^{2} ; r^{2}=0,87$

${ }^{4}$ efeito quadrático (quadratic effect): $Y=51,3800-5,3378 X+0,1661 X^{2} ; r^{2}=0,51$

5 efeito quadrático (quadratic effect): $Y=64,2352-3,8216 X+0,1204 X^{2} ; r^{2}=0,42$ ${ }^{*} \mathrm{p}<0,001 ;{ }^{* *} \mathrm{p}<0,01$
}

\section{R. Bras. Zootec., v.31, n.2, p.835-841, 2002 (suplemento)}



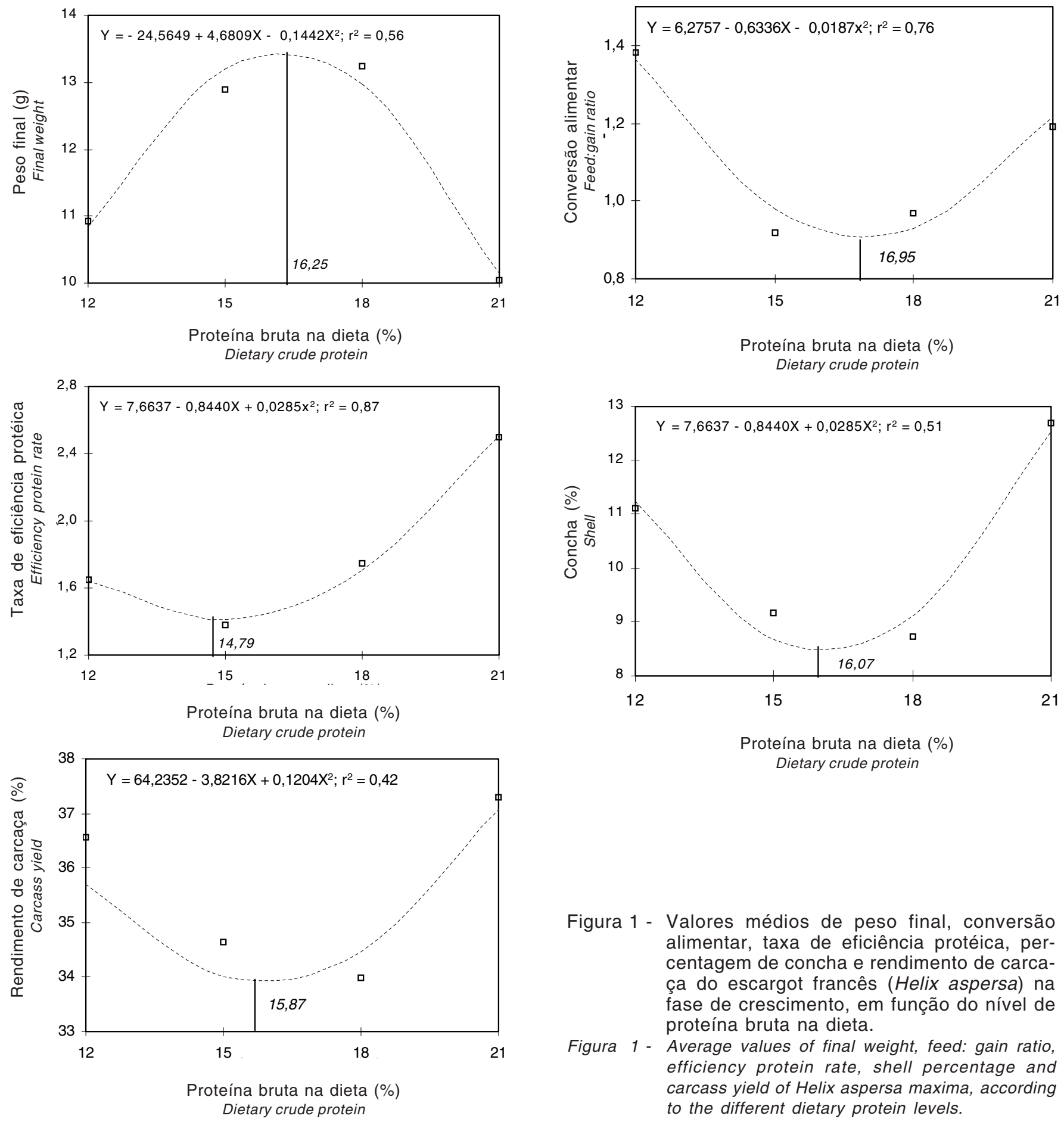

Figura 1 - Valores médios de peso final, conversão alimentar, taxa de eficiência protéica, percentagem de concha e rendimento de carcaça do escargot francês (Helix aspersa) na fase de crescimento, em função do nível de proteína bruta na dieta.

Figura 1 - Average values of final weight, feed: gain ratio, efficiency protein rate, shell percentage and carcass yield of Helix aspersa maxima, according to the different dietary protein levels.

em relação ao aumento dos teores de $\mathrm{PB}$ nas dietas para o caracol africano (A. fulica). Entretanto, o valor máximo estimado foi de $18,28 \%$ da dieta o qual é superior ao obtido para o $H$. aspersa.

Os valores médios obtidos para a conversão alimentar, taxa de eficiência protéica, percentagem de concha e rendimento de carcaça, apre-

sentaram efeito quadrático $(\mathrm{p}<0,001)$, em função dos teores de PB nas dietas. Entretanto, essas variáveis apresentaram valores mínimos estimados a 16,$95 ; 14,79 ; 16,07$ e $15,87 \%$ de PB, respectivamente. Resultados similares, porém com valores mínimos de PB estimados superiores, foram obtidos para A. fulica por Soares (1999). 
A taxa de sobrevivência, não foi afetada ( $p>0,01)$ pelas diferentes dietas utilizadas, fato que está de acordo com o obtido por Soares et al. (1999).

Os teores de PB necessários para os melhores índices das características de desempenho aqui obtidos para $H$. aspersa são inferiores aos encontrados por Soares et al. (1999) para o A. fulica, indicando diferenças de exigências nutricionais entre essas espécies.

A porcentagem de concha apresentou menor valor nas dietas (16,07\% de PB) (Figura 1). Dessa forma, este teor de PB possibilita a obtenção de animais com maior proporção de carne. O fato de os animais que receberam dietas com teores de $\mathrm{PB}$ próximos à exigência apresentarem valores de percentagem de concha inferiores aos que receberam dietas com teores acima e abaixo da exigência deve estar relacionado com o estado nutricional dos mesmos, em que os animais alimentados com dieta contendo teor adequado de PB apresentaram a melhor condição nutricional. Resultado similar foi encontrado por Soares et al. (1999), os quais observaram que indivíduos de A. fulica alimentados com dietas contendo cerca de $20,00 \%$ de $\mathrm{PB}$ (próximo à exigência desta espécie) apresentaram valores inferiores de porcentagem de concha que aqueles alimentados com teores inferiores de PB. Avaliando a composição química de A. fulica, Aboua (1990) observou que a proteína corresponde a $72,10 \%$ da matéria seca do músculo, enquanto a concha tem apenas $1,81 \%$ de proteína e elevados teores de cinzas. Dessa forma, a proteína dietária parece ser mais importante para a deposição no músculo do que na concha. Assim, teores baixos de PB não comprometem a formação da concha.

Os resultados deste estudo indicam que a exigência de PB para o escargot francês é de 16,07\%. Este valor é superior ao sugerido para caracóis de modo geral (15,00\%) por Ribas (1986). Entretanto, é inferior ao proposto para o A. fulica $(18,27 \%)$ por Soares et al. (1999) e Marks \& Jess (1994), que indicaram dietas com $17,00 \%$ de PB, para essa espécie.

Os valores médios da temperatura ambiente pela manhã e tarde foram de $15,05 \pm 5,21^{\circ} \mathrm{Ce} 20,26 \pm 3,75^{\circ} \mathrm{C}$, respectivamente, permanecendo dentro dos valores recomendados para a criação da espécie.

\section{Conclusões}

A exigência de proteína bruta para o caracol francês (Helix aspersa maxima) em fase de crescimento é de $16,25 \%$ da dieta.

\section{Literatura Citada}

ABOUA, F. Chemical composition of Achatina fulica. Tropicultura, v.8, n.3, p.121-122, 1990.

BARRIER, J. A criação do caracol. Lisboa: Litexa Portuga, 1982. 143p.

CUELlAR, R.C.; CARRASCO, L.C.; GARCIA, T.P. Helicicultura - Cria moderna de caracoles. Madrid: Mundi-Prensa, 1986. 142p.

EUCLYDES, R.F. Manual de utilização do programa SAEG (Sistema para Análises Estatísticas e Genéticas). Viçosa, MG: Universidade Federal de Viçosa, 1983. 59p.

FERRAZ, J. O escargot criação e comercialização. São Paulo: Ícone, 1999. 176p.

HANSSEN, J.E. Criação prática de escargots. São Paulo: Nobel, 1989. 113p.

HAYASHI, C.; FURUYA, V.R.B.; GALDIOLI, E.M. et al. Desempenho do escargot Achatina fulica, cultivados sob diferentes manejos. In: ENCONTRO BRASILEIRO DE MALACOLOGIA, 15., 1997, Florianópolis. Resumos... Florianópolis: 1997. p.97.

HAYASHI, C.; FURUYA, V.R.B.; FURUYA et al. Avaliação de diferentes níveis de cálcio para o escargot gigante (Achatina fulica) em fase de crescimento. In: REUNIÃO ANUAL DA SOCIEDADE BRASILEIRA DE ZOOTECNIA, 35., 1998a, Botucatu. Anais... Botucatu: Sociedade Brasileira de Zootecnia, 1998a. v.4. p.162-163.

HAYASHI, C.; SOARES, C.M.; FURUYA, W.M. et al. Efeito de diferentes níveis de cálcio em dietas para o escargot francês Helix aspersa maxima em fase de crescimento. In: REUNIÃO ANUAL DA SOCIEDADE BRASILEIRA DE ZOOTECNIA, 35., 1998b, Botucatu. Anais... Botucatu: Sociedade Brasileira de Zootecnia, 1998b. v.4. p.159-163.

HAYASHI,C.; SOARES, C.M.; BOSCOLO, V.R. et al. Diferentes fontes protéicas em dietas para o caracol gigante (Achatina fulica) na fase de crescimento. Revista Brasileira de Zootecnia, v.29, n.6, p.208-2086, 2000.

JAUNCEY, K.; ROSS, B. A guide to tilapia feeds and feeding. Scotland: University of Stirling, 1982. 111p.

LOBÃO, V.L.; BARROS, H.P.; HORIKAWA, M.T. Biologia e cultivo de escargots. Boletim do Instituto de Pesca, v.5, n.1, p.1-12, 1988.

MARKS, R.J.; JESS, S. Effects of dietary protein source and contend on growth of Helix aspersa var. maxima snails. Snail Farming Research, v.5, n.1, p.64-74, 1994.

MELO, S.G.; ROVERSO, E.A.; LOBÃO, V.L. Desenvolvimento ponderal do "escargot" Helix aspersa Müller (Gastropoda, Stylommatophora) com o emprego de diferentes fontes de cálcio. Boletim do Instituto de Pesca, v.18, n.(único), p.31-40, 1991.

MONNEY, K.A. Effects of different dietary regimes on growth and reproductive function of farmed Achatina fulica Bowdich. Snail Farming Research, v.5, n.1, p.14-22, 1994. 
PACHECO, P.; FÁTIMA MARTINS, M.; BATTERMARQUE, V. et al. Diferentes fontes de cálcio em dietas escargot gigante africano (Achatina fulica) e seu efeito no crescimento e rendimento de carcaça. Higiene Alimentar, v.12, n.1, p.43-46, 1998 .

RIBAS, J. Criação de caracóis - nova opção econômica brasileira. São Paulo: Nobel, 1986. 123p.

RODRIGUES, M.P. Manual prático para a criação de caracóis (escargots). 2.ed. São Paulo: Ícone, 1991. 123p.

ROSTAGNO, H.S.; SILVA, D.J.; COSTA, P.M.A. Composição de alimentos e exigências nutricionais de aves suínos. Viçosa, MG: Universidade Federal de Viçosa, 1994. 57p.
ROUSSELET, M. Cria del caracol. Madrid: Mundi Prensa, 1986. $144 \mathrm{p}$.

SOARES, C.M.; HAYASHI, C.; GONÇALVES, G.S. et al. Exigência de proteína para o caracol gigante (Achatina fulica) em fase de crescimento. Acta Scientiarum, v.21, n.3, p.683-686, 1999.

Recebido em: 19/06/01

Aceito em: 16/11/01 